ORIGINAL ARTICLE

\title{
Epidemiology of musculoskeletal pain in primary care
}

\author{
J De Inocencio
}

Arch Dis Child 2004;89:431-434. doi: 10.1136/adc.2003.028860

Correspondence to: Dr J De Inocencio, CS "Estrecho de Corea", Instituto Madrileño dé la Salud, Atención Primaria Area 4. C/Estrecho de

Corea 1, 28027 Madrid, Spain; deinocjm@

eresmas.net

Accepted

10 September 2003

\begin{abstract}
Aims: (1) To determine the proportion of children evaluated for musculoskeletal pain in a paediatric primary care clinic over a three year period; (2) to describe the number of office visits due to musculoskeletal pain; (3) to categorise the more common presenting complaints; and (4) to characterise the aetiology of musculoskeletal pain in a paediatric primary care clinic.

Methods: Retrospective chart review of all children $\geqslant 3$ and $<15$ years of age evaluated in an urban paediatric primary care clinic in Madrid between 1 January 1997 and 31 December 1999.

Results: (1) A total of 317 children were evaluated for musculoskeletal pain throughout the study. The prevalence of musculoskeletal pain increased as children grew older, from 2.4-5.7\% at age 3 to $27.5-$ $36 \%$ at age 14. Regression analysis showed that age (OR 1.20) and gender (OR 0.75 ) were associated with MSP. (2) Musculoskeletal pain was reported in 397 of 6500 office visits (6.1\%; $95 \% \mathrm{Cl} 5.5$ to $6.7 \%$ ). (3) Arthralgias and soft tissue pain represented $65 \%$ of the presenting musculoskeletal complaints. (4) Trauma was the most common aetiology, responsible for $44 \%$ of all musculoskeletal pain related office visits. Mechanical/overuse pathology (23.9\%) and osteochondroses (10.3\%) represented the second and third leading aetiologies.

Conclusions: Musculoskeletal pain is a common presenting complaint in primary care. The number of children presenting with musculoskeletal pain increases as they grow older, being particularly frequent among the adolescent population. The spectrum of aetiologies involved is limited, to the extent that three are responsible for almost $80 \%$ of cases.
\end{abstract}

l is common for children to complain of musculoskeletal pain (MSP). Surveys conducted in different countries at schools and paediatric clinics indicate that $4-15 \%$ of children develop skeletal pain..$^{1-5}$ A prospective study revealed that $6 \%$ of the visits to a paediatric primary care clinic (PPCC) of children older than 3 years of age were for MSP. ${ }^{6}$ Despite the prevalence of MSP in paediatrics, there is limited information available regarding its epidemiology and aetiology at a primary care level.

The study was undertaken to determine the number of children $\geqslant 3$ and $<15$ years evaluated for MSP in a PPCC during a three year period, to determine the number of office visits due to MSP, to categorise the more common clinical presentations, and to characterize its aetiology.

\section{PATIENTS AND METHODS}

The medical records of all children presenting to a National Health Service (NHS) PPCC located in Madrid, Spain, between 1 January 1997 and 31 December 1999 were reviewed. Inclusion criteria were: (1) age of patients between 3 and 14 years; (2) musculoskeletal evaluation requested because of pain by the family/patient or due to emergency room (ER) follow up; and (3) clinical chart available for review. The age limits were determined by the NHS requirement of transferring patient care to family physicians at age 14 years, and by the low frequency of MSP in children younger than 3 years. The medical records of patients who transferred their care to another PPCC were available from October 1997 to December 1999 due to modification of the chart forwarding procedure, which permitted the PPCC to retain copies of transferred patient's charts.

Paediatric health care in Spain is offered free of charge in clinics located no more than 30 minutes away from family residences. Patient assignment to PPCC is based on their residential geographic location, although parents might choose among paediatricians working in schedules that run from 8 am to $9 \mathrm{pm}$.
The number of children presenting with MSP was determined using one visit per child per year. The number of office visits due to MSP was calculated using every visit, duplicated (same presenting complaint) and unduplicated (different presenting complaint), for every child each year.

Presenting complaints were classified into seven groups: knee arthralgias, other joint (ankles, wrists, small joints of the fingers) arthralgias, soft tissue (muscles, ligaments, tendons) pain, and heel, hip, back, and bony pain. The category ER follow up was included to account for those children initially evaluated for MSP in the ER who required a follow up.

The aetiological categories considered included trauma (sprains, fractures, muscle contusion), mechanical/overuse syndromes (patellofemoral pain syndrome, overuse tenosynovitis, or muscle pain), osteochondroses (Osgood-Schlatter and Sever diseases), hypermobility (defined according to Beighton criteria $^{7}$ ), non-specific pain (self-limited pain with normal musculoskeletal exam), growing pains, arthralgias/myalgias associated with viral infection, toxic synovitis, and inflammatory arthritides (juvenile chronic arthritis, reactive arthritis).

Patellofemoral pain syndrome was defined as retropatellar knee pain elicited by restraining the patella during a quadriceps contraction, frequently accompanied by pain on compression of the patella. Growing pains were defined as episodes of deep aching, frequently diffuse pain in the shins, calves, or thighs, usually in the evening or during the night, which improved with massage, with no functional limitation, and a normal physical examination.

To facilitate interpretation of the data children were pooled into three groups: preschool, children 3-5 years of age; school, 6-9 years of age; and adolescent, 10-14 years of age.

Abbreviations: ER, emergency room; MSP, musculoskeletal pain; PPCC, paediatric primary care clinic 


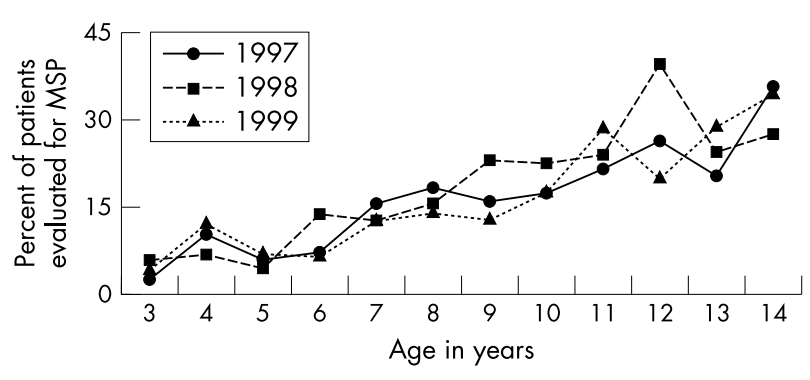

Figure 1 Percentage of patients evaluated for MSP according to their age and year of the study.

\section{Statistical methods}

Descriptive statistics were expressed as raw values and percentages. Patients were categorised according to their age. The $\chi^{2}$ test was used to compare categorical data, and the Fisher's exact test was used when the sample was equal to or less than five. A univariate regression analysis was performed, including those variables that reached a level of $\mathrm{p} \leqslant 0.2$ into a multivariate analysis. Statistical significance was set at 0.05 for all tests performed. The $95 \%$ confidence interval (CI) was used when reported.

\section{RESULTS}

\section{Population characteristics}

The number of children who received their paediatric care at the clinic ranged between 850 and 1000 children per calendar year, having a nearly equal female:male distribution. Seventy to seventy five per cent were age eligible for the study. Sixty to 100 children per year were lost to follow up because their families moved to a different geographic area. A similar number of children transferred to the clinic each year.

The number of children $\geqslant 3$ and $<15$ years of age followed at the PPCC ranged from 588 in 1997 to 660 in 1999. Three quarters of the children received routine care at the PPCC for at least two years $(52.6 \%$ were followed for three years, $24.8 \%$ for two years).

\section{MSP prevalence}

The number of children complaining of MSP varied with the age of children and the evaluation year (fig 1). A total of 317 children were evaluated throughout the study (89 in 1997, 117 in 1998, and 111 in 1999). Similar numbers of boys and girls complained of MSP in most groups at all ages (data not shown), although in the overall series a slight predominance of girls was observed ( $18.7 \% \vee 14.8 \%$; $\mathrm{p}=0.02$; OR $0.75,95 \%$ CI 0.59 to 0.96 ).

The pattern of consultation followed the same trend each year of the study; the proportion of children complaining of MSP increased as they grew older (fig 1). Univariate regression analysis confirmed that age $(\mathrm{p}<0.0001$, OR $1.20,95 \%$ CI 1.16 to 1.25$)$ and, to a lesser extent, gender $(p=0.02$; OR $0.75,95 \%$ CI 0.59 to 0.96$)$, were associated with MSP. Those findings were corroborated in a multivariate analysis, which did not show any significant interaction between the variables studied (age OR 1.20, 95\% CI 1.15 to 1.25; gender OR $0.78,95 \%$ CI 0.60 to 0.99$)$.

\section{Office visits due to MSP}

Of a total of 6500 office visits recorded in three years, 397 were due to MSP $(6.1 \%$; 95\% CI 5.5-6.7\%). The number of office visits, MSP related and total, varied each year (106/ 1778 in 1997, 150/2334 in 1998, and 141/2388 in 1999); differences, however, were not statistically significant. Office visits due to MSP were most frequent in adolescents, to the extent that in children 11-14 years of age MSP was responsible for $11.6 \pm 1.5 \%(206 / 1780)$ of all clinic visits. The number of visits due to MSP by groups was: preschool children 35/2145 (1.6\%), school aged 117/2169 (5.4\%), and adolescents 245/2186 (11.2\%).

\section{Characterisation of the presenting complaints}

Three presenting complaints, other joint arthralgias, soft tissue pain, and knee arthralgias, represented $65 \%$ of all complaints for all ages (table 1). The most prevalent was other joint arthralgias, although the affected joint varied with the age. Diffuse arthralgias were more common in preschool children (4/7 children, $57 \%)$ than in school children $(2 / 34,6 \%$; $\mathrm{p}<0.003)$ or adolescents $(0 / 58 ; \mathrm{p}<0.0001)$. The ankle was the most commonly affected joint among the school (15/ $34,44 \%)$ and adolescent $(20 / 58,34 \%)$ groups. Similarly, involvement of the joints of the fingers increased as children grew $(0 / 7$ in the preschool group, $7 / 34(20 \%)$ in school children, and $17 / 58(29 \%)$ in adolescents).

Preschool children reported more frequent hip and bony pain than older children, who complained more often of heel and back pain (table 1). Only the proportion of preschool children with hip pain differed from that in school aged children $(p=0.05)$ and adolescents $(p<0.005)$.

The category ER follow up included fractures $(\mathrm{n}=14)$, sprains $(n=7)$, osteochondroses $(n=5)$, and contusions $(n=4)$. Overall, MSP involved more frequently the lower extremities $(51 \%)$ than the upper extremities (39\%) or axial skeleton $(10 \%)$.

\section{MSP aetiology}

The most common MSP aetiology at all ages was trauma (table 2). Bone/muscle contusion was the most common trauma subgroup. It was more frequent in preschool children $(9 / 11,82 \%)$ than in school patients $(17 / 53,32 \%$; $<<0.05)$ or adolescents $(25 / 109,23 \%$; $p<0.0002)$. In contrast, fractures were recorded in no preschool children, 6/53 (11\%) school children, and 19/109 (17\%) adolescents.

Certain aetiologies presented an obvious age related pattern. Non-specific pain, growing pains, toxic synovitis, and hypermobility were much more common in preschool children (table 2 ). Toxic synovitis was diagnosed in $8 / 10$ before the age of 8 years, and in none after the age of 11 (preschool $v$ adolescents $\mathrm{p}=0.002$ ). Similarly, hypermobility was more frequent in preschool children than in adolescents $(p=0.01)$.

Table 1 Presenting complaints organised by age group

\begin{tabular}{|c|c|c|c|c|c|c|c|c|c|}
\hline & & Knee arthralgias & Other arthralgias & Soft tissue & Heel pain & Hip pain & Back pain & Bony pain & ER F/U \\
\hline Preschool & $\mathrm{n}(\%)$ & $7(20)$ & $7(20)$ & 9 (25.7) & - & $5(14.3)$ & $1(2.9)$ & $5(14.3)$ & $1(2.9)$ \\
\hline School & $\mathrm{n}(\%)$ & 15 (12.8) & $34(29.1)$ & $31(26.5)$ & $6(5.1)$ & $5(4.3)$ & $10(8.5)$ & $5(4.3)$ & $11(9.4)$ \\
\hline Adolescent & $\mathrm{n}(\%)$ & 47 (19.2) & 58 (23.7) & 50 (20.4) & $18(7.3)$ & $4(1.6)$ & 30 (12.2) & $20(8.2)$ & $18(7.3)$ \\
\hline Total & $\mathrm{n}(\%)$ & $69(17.4)$ & 99 (24.9) & 90 (22.7) & $24(6)$ & $14(3.5)$ & $41(10.3)$ & $30(7.6)$ & $30(7.6)$ \\
\hline
\end{tabular}

Children of 3-5 years of age $(n=35)$ were pooled in the "preschool" group, children of 6-9 years $(n=117)$ in the "school" group, and those aged 10-14 years $(\mathrm{n}=245)$ in the "adolescent" group. ER F/U, emergency room follow up. 
Table 2 Aetiological categories organised by age group

\begin{tabular}{|c|c|c|c|c|c|c|c|c|c|c|}
\hline & & Traumatic & Mech/overuse & Osteochond & Hypermob & Non-specific & $\begin{array}{l}\text { Growing } \\
\text { pains }\end{array}$ & Viral infx & $\begin{array}{l}\text { Toxic } \\
\text { synov }\end{array}$ & Inflamm \\
\hline Preschool & $\mathrm{n}(\%)$ & $11(31.4)$ & $1(2.9)$ & - & $4(11.4)$ & $6(17.1)$ & $6(17.1)$ & $3(8.6)$ & $4(11.4)$ & - \\
\hline School & $\mathrm{n}(\%)$ & $53(45.3)$ & 21 (17.9) & $13(11.1)$ & $4(3.4)$ & $7(6)$ & $7(6)$ & $8(6.8)$ & $4(3.4)$ & - \\
\hline Adolescent & $\mathrm{n}(\%)$ & 109 (44.5) & $73(29.8)$ & $28(11.4)$ & $5(2)$ & $17(6.9)$ & $1(0.4)$ & $7(2.9)$ & $2(0.8)$ & $3(1.2)$ \\
\hline Total & $\mathrm{n}(\%)$ & $173(43.6)$ & $95(23.9)$ & $41(10.3)$ & $13(3.3)$ & $30(7.6)$ & $14(3.5)$ & $18(4.5)$ & $10(2.5)$ & $3(0.8)$ \\
\hline
\end{tabular}

Children of 3-5 years of age $(n=35)$ were pooled in the "preschool" group, children of 6-9 years $(n=117)$ in the "school" group, and those aged 10-14 years $(\mathrm{n}=245)$ in the "adolescent" group.

Mech/overuse, mechanical/overuse syndromes; Osteochond, osteochondroses; Viral infx, viral infection; Toxic synov, toxic synovitis; Inflamm, inflammatory

arthritides.

Adolescents presented more frequently with mechanical/ overuse syndromes than preschool $(p=0.001)$ or school children $(\mathrm{p}=0.02)$. Osteochondrosis, recorded in $11 \%$ of adolescents, was not detected in preschool children $(\mathrm{p}=0.03)$.

The same presenting complaint could be due to different aetiologies. Soft tissue pain was reported with similar frequencies across all age pools (table 1). The leading aetiology, however, was growing pains in preschool children $(6 / 9,67 \%)$, trauma in school children $(11 / 31,35 \%)$, and overuse syndromes in adolescents $(33 / 50,66 \%)$. Knee arthralgias in preschool children were non-specific $(4 / 7,57 \%)$ or associated with hypermobility $(2 / 7,29 \%)$, whereas in school children and adolescents they were most commonly due to patellofemoral pain syndrome $(8 / 15,53 \%$; and $24 / 47,51 \%)$, trauma $(3 / 15,20 \%$; and $10 / 47,21 \%)$ and Osgood-Schlatter disease $(2 / 15,13 \%$; and $9 / 47,19 \%)$. Bony pain in most preschool children was associated with a normal physical examination, while $50 \%$ of adolescents with this complaint had fractures.

Three of 397 clinic visits due to MSP $(0.8 \%)$ were due to inflammatory arthritides. All were recorded in adolescents (3/ 245 consultations, $1.2 \%$ ) and were categorised as reactive arthritis.

\section{DISCUSSION}

This study represents the first comprehensive description of the epidemiology of musculoskeletal pain in children from a primary care perspective. Other series have addressed paediatric MSP with a more restrictive approach, limiting their scope to growing pains, ${ }^{3}{ }^{4}$ recurrent limb pain, ${ }^{5}$ nonspecific musculoskeletal pain, ${ }^{8}$ or pain limited to the lower limbs. ${ }^{9}$ The setting, a PPCC, provides more realistic figures of the actual prevalence of these complaints than studies performed at tertiary centres, where referral bias is more likely to occur. All evaluations were done by the same investigator, ensuring that the same examination technique and diagnostic criteria were applied.

This series confirms that musculoskeletal complaints are more common as children grow older, being particularly frequent in adolescents.

MSP was responsible for $6.1 \%$ of the office visits of children between 3 and 14 years of age, and more than 10\% of those of adolescents. Similar rates have been described by other series. ${ }^{12}$ The US National Ambulatory Medical Care Survey of 1977-78 reported that musculoskeletal complaints comprised 7\% of children's visits to their physician. ${ }^{2}$ More recently, Ziv et al analysed the 1994 US National Ambulatory Medical Care Survey data, restricting their study to an adolescent population. ${ }^{1}$ The authors concluded that musculoskeletal complaints constituted the third leading category for office visits in the USA, being responsible for $9.7 \pm 1.5 \%$ of all $11-14$ year old visits. A similar number, $11.5 \pm 1.4 \%$, has been obtained in the present series.

Three presenting complaints, arthralgias of the knees, arthralgias of other joints, and soft tissue pain represented two thirds of all complaints. Therefore, the most commonly involved areas are readily accessible and might be easily assessed by paediatricians with adequate training in musculoskeletal examination.

The leading aetiology of MSP at all ages was trauma, whereas other aetiologies showed a preferential distribution according to the age of children. Interestingly, the same complaint did indeed have different causes depending of the age of the child. The absence of children with idiopathic musculoskeletal pain in the series indicated that the spectrum of aetiologies of MSP in primary care differed from that recorded in tertiary centres. ${ }^{10-17}$ Similarly, there were no cases of underlying neoplasia ${ }^{18}$ or chronic arthritis. ${ }^{19}$

There are significant methodological differences between this study and other series. Some were surveys conducted at paediatric clinics ${ }^{12}$ or schools. ${ }^{3-589}$ Other studies required from one episode of skeletal pain a week ${ }^{8}$ to two a year ${ }^{5}$ for inclusion, or excluded patients with MSP due to injury. ${ }^{38}$ This report concerns children who requested an evaluation because of musculoskeletal pain, regardless of its location, duration, aetiology, or accompanying symptoms.

Limitations of this study include its retrospective design. Records of children who transferred to another PPCC before October 1997 were not available for review, which may substantiate the nearly $20 \%$ decrease in the number of consultations recorded in 1997. In addition, the study was performed in a single clinic by a single investigator. The setting of the study, an easily accessible free-of-charge NHS clinic, may potentially result in an increased number of consultations that may not have taken place in other health organisation environments. Therefore, to what extent the findings reported in this series can be generalised to other practice environments remains to be determined.

\section{ACKNOWLEDGEMENTS}

I wish to thank Daniel Lovell MD, MPH and Luis Benito MD for their thorough review of the manuscript and helpful comments.

\section{REFERENCES}

1 Ziv A, Boulet JR, Slap GB. Utilization of physician offices by adolescents in the United States. Pediatrics 1999;104:35-42.

2 DHHS. Vital and health statistics. Patients' reasons for visiting physicians: National Ambulatory Medical Care survey, U.S. 1977-78, DHHS publication number 82-1717, National Center for Health Statistics, Hyattsville, Maryland, 1981.

3 Naish JM, Apley J. Growing pains: a clinical study of non-arthritic limb pains in children. Arch Dis Child 1951;26:134-40.

$4 \varnothing$ ster J, Nielsen A. Growing pains. A clinical investigation of a school population. Acta Paediatr Scand 1972;61:329-34.

5 Abu-Arafeh I, Russell G. Recurrent limb pain in schoolchildren. Arch Dis Child 1996;74:336-9.

6 De Inocencio J. Musculoskeletal pain in primary pediatric care. Analysis of 1,000 consecutive general pediatric clinic visits. Pediatrics 1998;102:e63.

7 Beighton PH, Solomon L, Soskolne CL. Articular mobility in an African population. Ann Rheum Dis 1973;32:413-18.

8 Mikkelsson M, Salminen JJ, Kautiainen H. Non-specific musculoskeletal pain in preadolescents. Prevalence and 1-year persistence. Pain 1997;73:29-35. 
9 Shrier I, Ehrmann-Feldman D, Rossignol M, et al. Risk factors for development of lower limb pain in adolescents. J Rheumatol 2001;28:604-9.

10 Sherry DD, McGuire T, Mellins EM, et al. Psychosomatic musculoskeletal pain in childhood: clinical and psychological analyses of 100 children. Pediatrics 1991;88:1093-9.

11 Malleson PN, Al-Matar M, Petty RE. Idiopathic musculoskeletal pain syndromes in children. J Rheumatol 1992;19:1786-9.

12 Southwood TR. Recent developments in the understanding of paediatric musculoskeletal pain syndromes. Ann Rheum Dis 1993:52:490-2.

13 Szer IS. Musculoskeletal pain syndromes that affect adolescents. Arch Pediatr Adolesc Med 1996;150:740-7.

14 Aasland A, Flatö B, Vandvik IH. Psychosocial factors in children with idiopathic musculoskeletal pain: a prospective, longitudinal study. Acta Paediatr 1997;86:740-6.
15 Sherry DD. Musculoskeletal pain in children. Curr Opin Rheumatol 1997;9:465-70.

16 Song KM, Morton AA, Koch KD, et al. Chronic musculoskeletal pain in childhood. J Pediatr Orthop 1998;18:576-81.

17 Sherry DD. An overview of amplified musculoskeletal pain syndromes. J Rheumatol 2000;27(suppl 58):44-8.

18 Trapani S, Grisolia F, Simonini G, et al. Incidence of occult cancer in children presenting with musculoskeletal symptoms: a 10-year survey in a pediatric rheumatology unit. Semin Arthritis Rheum 2000;29:348-59.

19 McGhee JL, Burks FN, Sheckels JL, et al. Identifying children with chronic arthritis based on chief complaints: absence of predictive value for musculoskeletal pain as an indicator of rheumatic disease in children. Pediatrics 2002;110:354-9.

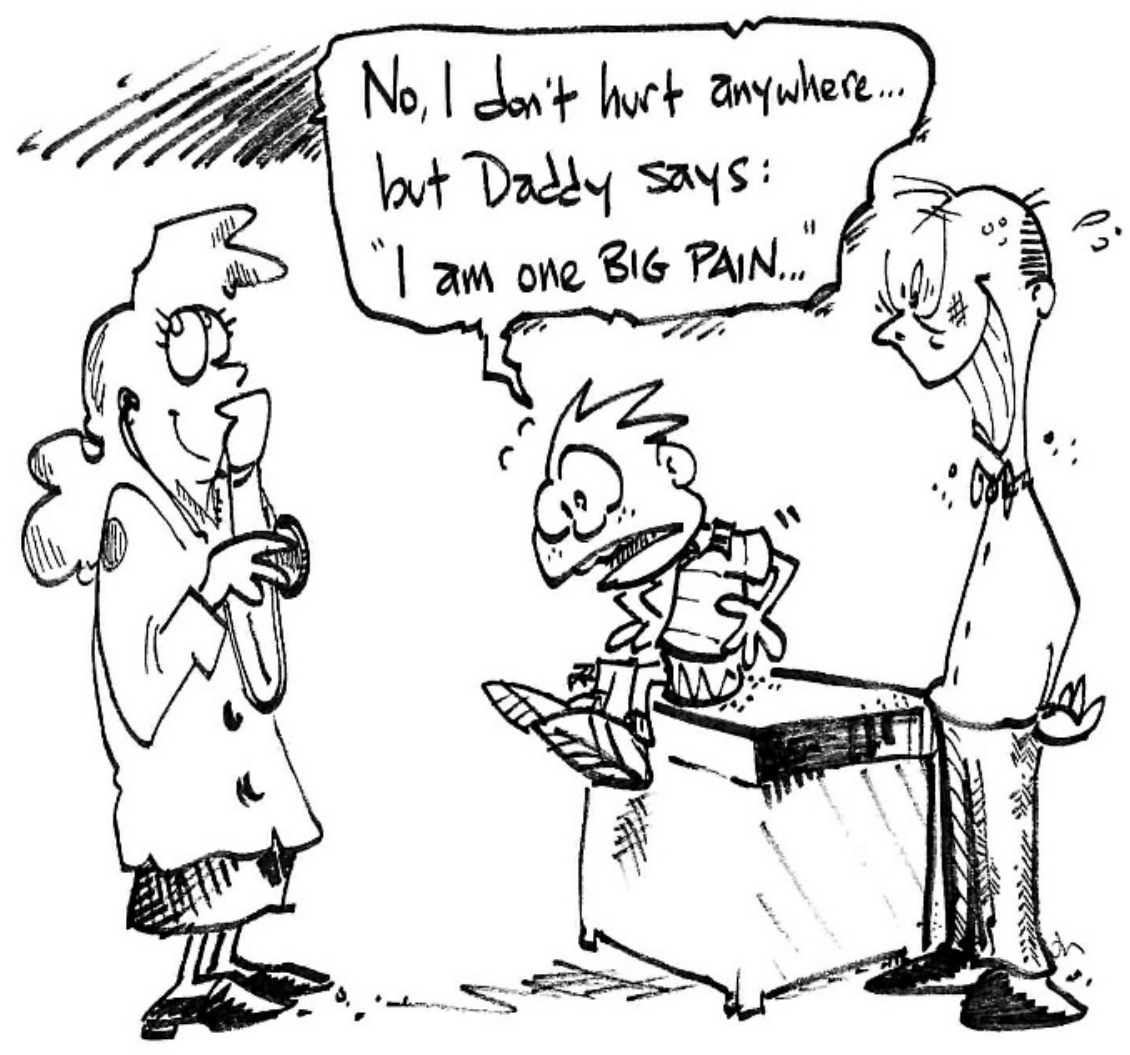

